\title{
Edna St. Vincent Millay: versões de uma efêmera beleza
}

José Lira

Não me lembro de que antiga antologia em língua inglesa extraí os seis poemas de Edna St. Vincent Millay que compõem este trabalho. Pus muita coisa no papel e na memória, nos meus tempos de rapaz que lia todos os livros e não podia comprar nenhum. Como os papéis se extraviam e a memória é falha, também não sei se havia outros textos da mesma autora na antologia. $O$ fato é que, ao revirar gavetas e rever esses poemas, resolvi traduzi-los. Foram essas, aliás, as primeiras traduções poéticas que me aventurei a fazer, e isto me deixa à vontade para expor as suas justificáveis deficiências. É da tradução desses poemas que vou falar neste texto, levando em conta apenas o seu valor, a bem dizer, sentimental, não o seu suposto valor como obra literária; afinal de contas, não há nenhuma razão, já disse alguém, para que uma pessoa goste de um mesmo poema (ou de sua tradução) a vida inteira.

São essas questões de gosto, instáveis e mutáveis através dos tempos, que - muito mais do que as tendências indicadas pelas teorias do momento e refletidas nas sucessivas reavaliações dos cânones literários - definem a inclusão desse ou daquele autor na preferência pessoal de um leitor como eu: um leitor comum, que vê um poema como um poema e não como matéria 
para ensaios crípticos de hermenêutica literária. No caso de Edna St. Vincent Millay, não posso negar que, apesar de já não gostar tanto de tantos dos seus versos que tanto me encantaram em outros tempos, ainda hoje leio com prazer alguns dos seus poemas. E compartilho da obsessão de Manuel Bandeira (1974: 97): "Nome fabuloso Edna St. Vincent Millay: é um verso, é uma maravilha! Quantas vezes me tenho surpreendido a repetir Edna St. Vincent Millay, Edna St. Vincent Millay, Edna St. Vincent Millay, como repito um verso de Villon ou de Racine ou de Mallarmé!"

Edna St. Vincent Millay (1892-1950) foi uma das mais populares figuras literárias de seu tempo nos Estados Unidos. Tanto a crítica quanto o público viam nela uma das maiores expressões poéticas da literatura norte-americana; alguns chegaram a equiparar os seus sonetos aos de Shakespeare. Os livros que publicou no início da carreira (Renascence, A few figs from thistles, Second April e The harp-weaver, este último ganhador do Pulitzer Prize), continuaram a ser vendidos por várias décadas e deram-lhe condições de viver apenas de sua poesia, coisa rara para uma mulher em sua época.

Pertinaz partidária da poesia tradicional, Millay não se rendeu aos encantos do verso livre e, ainda no gozo da sua imensa fama junto ao público, foi "enterrada" pela crítica, que pugnava pela propagação do modernismo e pela intelectualização da poesia. I. A. Richards (1997: 58-74) chegou a usar um de seus sonetos como exemplo de "incoerências", "truques de estilo", "ressonâncias vazias" e outras mazelas, apontando nela um "querer dizer em definitivo", ou seja, a inclinação pela grandiloqüência que seria uma das fraquezas de todos os maus poetas líricos. Millay, que se voltou algumas vezes para a poesia panfletária, transformando a rebeldia juvenil em atos de contestação política, teve o mesmo destino de outros poetas contemporâneos, como Robert Frost e Sara Teasdale, os quais, famosos e festejados em vida, acabaram semi-excluídos do cânon norte-americano (Sara 
Teasdale, na verdade, desacreditada por seu sentimentalismo sem freios, foi excluída por completo e há muito tempo não figura sequer nas coletâneas poéticas femininas).

Os textos de que me servi para as traduções foram, depois de desengavetados, confrontados com uma coleção de poemas da autora, para sanar eventuais lapsos (que havia alguns) de minhas transcrições. São duas miniaturas, dois poemas curtos e dois sonetos: seis tentativas de recriação artística que, se não resultaram inteiramente perdidas, me causaram muita frustração como aprendiz do ofício de tradução. Pouca coisa saiu como eu queria. Hoje sei que há poemas que resistem a uma boa tradução, por razões que às vezes nem o tradutor saberia apontar. Pelas horas vividas sem prazer - que esta é, muitas vezes, a maldição do ofício - fui recompensado, no entanto, com alguns breves momentos de satisfação.

Vou começar com a pior tradução entre todas as seis, e que trata exatamente do mais famoso poema de Millay - tão famoso que se fixou no imaginário popular e perdeu sua referência autoral, passando a ser visto por uns como uma obra anônima ou atribuído por outros a diferentes autores (um dos quais Emily Dickinson, cuja escrita não tem a menor semelhança com a de Millay, mas que teve também alguns poemas curtos, como este de que agora falo, bastante popularizados). Este pequenino poema tornou-se um verdadeiro hino de batalha para os jovens, embriagados pelo êxtase da "era do jazz", no período do pós-guerra e da pré-depressão dos anos 20 do Séc. XX. "First Fig" é o título do poema, do livro A few figs from thistles (Alguns figos de urtigas), cujo título foi extraído da Bíblia (Mateus, 7.16: "Porventura coIhem-se uvas de espinhos ou figos de urtigas?", ou seja, "Are grapes gathered from thorns, or figs from thistles?"). "Figo n. ${ }^{\circ}$ " foi o título que dei à tradução, deixando claro que as minhas dificuldades começaram justamente do começo, com a perda da expressiva aliteração do título original: 
My candle burns at both ends;

It will not last the night;

But ah, my foes, and oh, my friends -

It gives a lovely light!

A minha vela queima dos dois lados;

Esta noite não dura;

Mas ah, meus inimigos e oh, meus camaradas -

Sua luz é tão pura!

"Nas duas pontas" traduziria "at both ends" com mais precisão. As aliterações dos dois últimos versos não foram recuperadas (se bem que várias outras opções, como, por exemplo, "adversários" e "aliados", não serviriam). O termo "camaradas" tem marcas semânticas e culturais entre nós que o inequívoco "friends" não autoriza. Além do mais, "pura" não traduz "lovely" com exatidão, a forma adverbial "tão" foi adicionada e o sintagma verbal "it gives" foi omitido na tradução, e o esquema métrico 7-6-8-6 foi esticado para 10-6-12-6, comprometendo seriamente a leveza do poema original. Por fim, as rimas perfeitas dos versos ímpares se perderam.

É assim que se expressam, com freqüência, os críticos literários e os teóricos dos estudos tradutórios, que se apegam aos mínimos detalhes, em suas observações e comentários, para julgar defectiva uma tradução. Até os adeptos da tradução "inventiva" ou "criativa", que em tese deveriam deixar o tradutor à vontade para - sim - para inventar e criar, não resistem à tentação de dar as suas bordoadas. $\bigcirc$ que marca a leitura de um poema em sua forma "original" é a visão de conjunto; o que guia a leitura de uma tradução, no entanto, é a busca obsessiva de todo tipo de "desvios" e senões. Mas eu me rendo aqui às evidências: esta não é, realmente, o que se poderia chamar uma tradução "feliz". 
○ "Second Fig" ("Figo n. ${ }^{\circ}$ 2"), a exemplo do título do livro e do poema já visto, cuja "vela" é a "lâmpada" ou "candeia" de Mateus, 6.22 -, também tem raízes no mesmo livro da Bíblia (Mateus, 7.26, 27). Só há, por sinal, esses dois "figos" em A few figs from thistles; os demais poemas têm títulos independentes:

Safe upon the solid rock the ugly houses stand:

Come and see my shining palace built upon the sand!

Sobre a sólida pedra firme se faz tanta casa feia:

Vem ver o meu palácio reluzente erguido sobre a areia!

Aqui também a métrica foi expandida, mas isto pode passar despercebido em versos mais longos como esses. E aqui a minha boa estrela me deu duas rimas perfeitas e facílimas de achar. Mas o fato é que o poema é tão curto, diria um crítico, que o tradutor não teve tempo de cometer erros.

Pois vamos agora a dois textos não tão curtos, ambos de Second April. "Travel" ("Viagem") é outro desses poemas que deram fama a Millay, recitados de cor em salas de aula e em salões de festas (no tempo em que a poesia era recitável, não dizível, legível ou só "visível"). Celebração do ato de viajar ou apologia do escapismo, este é um poema que ainda hoje me agrada e que me agradou traduzir:

The railroad track is miles away,

And the day is loud with voices speaking,

Yet there isn't a train goes by all day

But I hear its whistle shrieking. 
All night there isn't a train goes by,

Though the night is still for sleep and dreaming

But I see its cinders red on the sky,

And hear its engine steaming.

My heart is warm with the friends I make,

And better friends I'll not be knowing,

Yet there isn't a train I wouldn't take,

No matter where it's going.

A léguas de distância está a ferrovia

E o dia grita e fala sem parar,

E bem não há um trem que passa todo o dia,

Mas eu o ouço apitar.

Bem não há esse trem que a noite toda passa,

E a noite dorme e vai sonhar em paz,

Mas vejo o céu tingir-se em brasas e fumaça

E ouço o ofegar que ele faz.

Meu coração se apraz em boa companhia

E melhores amigos não terá,

Mas não existe um trem no qual eu não iria,

Aonde quer que ele vá.

Consegui manter ou recriar, sem muito esforço, algumas das mais evidentes características formais do poema: a alternância de rimas masculinas e femininas (com troca de lugar nos versos pares e ímpares) e as assonâncias do gerúndio em 'ing', transforma- 
das nas oxítonas em ' $a$ '. E como eu gosto deste poema e gosto da tradução que fiz, não vou apontar nenhum defeito.

"City Trees" ("As árvores das ruas") é outro poema cuja tradução não me deu trabalho, exceto por um detalhe, sem falar de novo na questão da métrica. Aliás, para não ter de falar de novo nessa questão, valho-me de Paulo Vizioli (1983: 113), que aponta o que chama de "discrepância silábica" como um sério problema na tradução de poesia de língua inglesa: "o texto traduzido para o vernáculo, via de regra, necessita de um número muito maior de sílabas que o texto original", pois as palavras inglesas "(principalmente as de origem teutônica) são menos longas que as da nossa língua". O esquema original de "City Trees" mudou de 8-8-8-6 para 10-10-10-8, discrepância que teria sido aprovada por Vizioli (1983: 115): "em quase todos os meus trabalhos de tradução aumentei propositalmente, de pelo menos duas sílabas, os versos dos poemas". Vamos ao poema:

The trees along this city street,

Save for the traffic and the train,

Would make a sound as thin and sweet

As trees in country lanes.

And people standing in their shade

Out of a shower, undoubtedly

Would hear such music as is made

Upon a country tree.

O little leaves that are so dumb

Against the shrieking city air,

I watch you when the wind has come -

I know what sound is there. 
As árvores ao longo destas ruas, Não fosse pelo trânsito ou o trem, Teriam esses sons de folhas nuas Que lá nos campos elas têm.

E qualquer um que abrigo lhes pedisse,

Na chuva ocasional, certo seria

Que a doce voz das árvores ouvisse,

Como nos campos ouviria.

Ó frágeis folhas que viveis em luta

Contra os ruídos que a cidade faz,

Sempre que o vento vem eu fico à escuta -

Eu sei que música ele traz.

Que são "folhas nuas"? Há folhas "nuas"? Admito que não sei. Sob o pretexto de dar uma "amostra dos perigos por que passa o tradutor nessa 'luta mais vã' que é lutar, não com palavras apenas, mas com palavras e rimas", eu havia criticado, num trabalho anterior (2000: 81-82), a tradução de um poema de Wordsworth ("No motion has she now, no force; / She neither bears nor sees; / Rolled round in earth's diurnal course, / With rocks, and stones, and trees") feita por Fernando Pessoa: "Já não ouve nem vê, nem força nua / Ou movimento encerra; / Arrastada co'a rocha e a erva sua / Na rotação da terra". "Foi a insistência em encontrar a rima perfeita para sua tradução", dizia eu, "que pôs a perder todo o trabalho de Pessoa nestes versos. Aquelas duas palavrinhas que não parecem ter o menor sentido, 'nua' e 'sua', exercem uma única função no texto: garantir a rima". Bem feito para mim, que também tive de me submeter a esse vexame. Mas agora advogo em causa própria: se os poetas se valem de 
"licenças poéticas" para melhor expressar as suas idéias, por que ao tradutor de poesia não poderiam ser permitidas certas "licenças tradutórias"? Ao poeta o que é do poeta, ao tradutor o que Ihe for possível obter. Na tradução poética, certas acomodações sintáticas e |ou semânticas e | ou pragmáticas se fazem absolutamente necessárias. Mais ainda se há exigências de métrica e rima a satisfazer. Recorro outra vez a Bandeira (1974: 96), que recomendava ao tradutor, ao traduzir um poema, "apurar o que é essencial nele e o que foi introduzido por exigência técnica, sobretudo de métrica e rima". Pois bem, se o poeta introduz algo não essencial em seu texto "por exigência técnica", por que um tradutor não pode fazer o mesmo? Eu precisava de uma rima para "ruas". Faltou-me técnica, talvez, para cumprir essa exigência, mas foi esta a rima que achei.

Os sonetos não são o que fiz de melhor nestas traduções. São o que pude fazer na tentativa de captar a dicção quase etérea de Millay, essa maestria em falar do amor romântico com uma voz tão pura, como quem fala de algo que viu e que sentiu pela primeira vez, que foi o que cativou os seus críticos de primeira hora. Abstenho-me de comentar estas duas últimas traduções para não ocupar muito espaço com a sucessão de seus inumeráveis problemas. Também não vou apontar nenhum eventual achado mais feliz, se é que algum há. Deixo essas tarefas ao leitor e à leitora que me seguiram até aqui. Diria apenas que, em meu afã de tradutor de poucos recursos, tive de deixar de lado certas preocupações mais pontuais, traindo às vezes a dicção original para ser fiel ao texto como um todo.

O primeiro soneto é outra vez do livro A few figs from thistles. Millay não usava dar títulos aos sonetos e, embora tivesse perpetrado muitos deles ao estilo petrarquiano, preferia o acabamento formal e o arranjo gráfico à inglesa, sem separação dos quartetos e tercetos (ou, nestes casos, dos quartetos e do dístico final): 
I shall forget you presently, my dear, So make the most of this, your little day, Your little month, your little half a year, Ere I forget, or die, or move away, And we are done forever; by and by I shall forget you, as I said, but now, If you entreat me with your loveliest lie I will protest you with my favourite vow. I would indeed that love were longer-lived, And oaths were not so brittle as they are, But so it is, and nature has contrived To struggle on without a break thus far, Whether or not we find what we are seeking Is idle, biologically speaking.

Brevemente, meu bem, vou esquecer-te, Por isso tens de aproveitar, agora, Tudo de bom que o tempo há de trazer-te, Antes que de uma vez eu vá embora, E o nosso amor acabe; um dia desses Sei que vou te esquecer; mas no momento, Se com doces mentiras me envolvesses, Eu te daria o meu consentimento. Quisera eu que o nosso amor durasse E não fossem as juras sem sentido, Mas assim são as coisas, e este impasse Juntos até aqui nos tem mantido Se é ou não é feliz nossa procura, Biologicamente, ela não dura. 
O segundo soneto, que formalmente segue o mesmo "breathholding style" do anterior, com uma única pausa no oitavo verso, é de Second April:

When I too long have looked upon your face, Wherein for me a brightness unobscured Save by the mists of brightness has its place, And terrible beauty not to be endured, I turn away reluctant from your light, And stand irresolute, a mind undone, A silly, dazzled thing deprived of sight From having looked too long upon the sun. Then is my daily life a narrow room In which a little while, uncertainly, Surrounded by impenetrable gloom, Among familiar things grown strange to me Making my way, I pause, and feel, and hark, Till I become accustomed to the dark.

Quando o teu rosto longamente fito, E nele a luz ao brilho se mistura, Por entre névoas de clarões hesito E a terrível beleza me tortura, E fujo dessa luz que me conquista, E atarantada fico, alheia a mente, Pobre criatura que perdeu a vista Ao olhar para o sol diretamente.

E assim a minha vida é um quarto estreito No qual por um momento me confundo, 
E a treva impenetrável eu espreito

Como uma estranha no meu próprio mundo,

E sigo, e paro, e a tatear procuro,

Até que me acostumo com o escuro.

Depois que reli esses poemas para escrever este texto é que notei que todos eles falam de coisas que vêm e que passam e se desfazem e se desmancham e de sentimentos e sensações que brilham por um momento e se perdem no vazio: o trem, o vento, o castelo na areia, a vela a arder, o amor de juras desfeitas, o fulgor da beleza num quarto escuro. Não haveria nisto tudo uma cruel ironia em relação à fugaz presença de Edna St. Vincent Millay no cânon literário norte-americano? Será que uma leitura mais ampla da obra poética de Edna St. Vincent Millay revelaria essa "temática do efêmero"? (Mas quem, nos tempos atuais, estaria preocupado com a leitura crítica de uma obra poética tão singela? Que tem ainda a dizer essa artesã de cuja agulha e linha não saiu nada mais vistoso que esse bordado ingênuo e esse adereço sentimental das "poesias de amor"?)

Ao rever o ínfimo resultado das minhas traduções, me tocou e me pungiu essa impressão de transitoriedade e a constatação de que algo mais se perdeu além de um simples nome, ah, Edna St. Vincent Millay, e de alguns poemas de um tempo em que a vida e a poesia eram as águas de outro rio, oh, Edna St. Vincent Millay.

Mas perdeu a poesia ou perdi eu?

\section{REFERÊNCIAS BIBLIOGRÁFICAS}

BANDEIRA, Manuel; ANDRADE, Mário de. Itinerários: cartas a Alphonsus de Guimaraens Filho. São Paulo: Duas Cidades, 1974. 
LIRA, José. "A invenção da rima na tradução de Emily Dickinson", in Cadernos de Tradução n. VI, UFSC, 2000.

MILLAY, Edna St. Vincent. Collected poems. Nova York: Harper Collins, 1975.

SARAIVA, Arnaldo. Fernando Pessoa: poeta-tradutor de poetas. Rio de Janeiro: Nova Fronteira, 1999.

RICHARDS, I. A. A prática da crítica literária. Trad. Almiro Pisetta e Lenita M. a Rímoli Esteves. São Paulo: Martins Fontes, 1997.

VIZIOLI, Paulo. "A tradução de poesia em língua inglesa: problemas e sugestões", in Tradução \& Comunicação, n. 2, 1983.

\section{SOBRE O TRADUTOR}

José Lira nasceu na Paraíba e mora há vinte anos em Recife. É mestre em Letras pela UFPE e dedica-se atualmente à tradução de Emily Dickinson (1830-1886) e outros poetas de língua inglesa. Publicou Poetry in the Classroom (2004), Breves Histórias do Brazil (2005) e Emily Dickinson e a poética da estrangeirização (2006), além de diversos trabalhos em livros e periódicos, na área da crítica literária e dos estudos tradutórios. Tem no prelo uma coletânea de 245 traduções de poemas de Emily Dickinson. 